\title{
Histopathological spectrum of Adult Nephrotic Syndrome over 16 years at a Tertiary Care Center in Mumbai with Clinicopathological, Electron Microscopy and Immunoflurescence Correlation of Renal Biopsies
}

\author{
Ganesh Ramdas Kshirsagar*, Nitin Maheswar Gadgil, Sangeeta Ramulu Margam, \\ Chetan Sudhakar Chaudhari, Prashant Vijay Kumavat and Sheela Jayawant Pagare
}

Department Of Pathology, Lokmanya Tilak Municipal Medical College and General Hospital, Sion, Mumbai (Maharashtra), India.

\section{ABSTRACT}

Background: The pattern of diseases causing adult nephrotic syndrome varies globally as well as in India. The aim of our study was to analyze the spectrum of patients with biopsy proven nephrotic syndrome in adults over 15 years, in respect with incidence, age distribution and correlate the clinicopathological features, electron microscopy and immunofluorescence.

Methods: We have evaluated and analyzed retrospectively 263 renal biopsies of adult nephrotic syndrome over a consecutive period of 16 years (January 2000 to December 2015) in our tertiary care Hospital.

Result: In our study of 235 (89.35\%) adequate renal biopsy cases overall male predominance was seen (M: F ratio 1.7:1) with maximum males noted in diabetic nephropathy (M: F ratio 4:1) while SLE was seen exclusively in female (M: F ratio 0:6). Minimal change disease (26.38\%), followed by MPGN (16.17\%) and FSGS (15.74\%) were the common histopathological lesions. In 15-45 years age majority of $78.72 \%$ cases were observed with prominently histomorphological pattern as MCD( $25.10 \%$ ), followed by FSGS ( $13.61 \%$ ) \& MPGN (13.19\%). In 45-85 years age , $21.28 \%$ cases majority were of membranous glomerulonephritis (5.10\%) and diabetic nephropathy (4.25\%). Primary glomerular diseases accounted for $78.3 \%$ cases commonest was MCD (26.38\%) and secondary glomerular diseases in $21.7 \%$ of cases, most common being amyloidosis (7.23\%) Light microscopy, immunopathology findings correlated with electron microscopy findings in 79 cases $(91.86 \%)$ out of 86 cases. Sample error was main reason of non correlation of EM \& LM diagnosis, especially in FSGS.

Conclusion: This data analysis is essential to study the prevalence of biopsy proven renal diseases and its variation and distribution as per age .Which can improve the understanding of utility of renal biopsy for future research of renal parenchymal diseases in adults.

Keywords: Nephrotic Syndrome, Renal Biopsy, Minimal Change Disease, Glomerulonephritis, Electron Microscopy.

\section{Introduction}

Richard Bright (1827) correlated for the first time the frequent occurrence of renal lesion in patient with dropsy and albuminous urine, ${ }^{[1]}$ which was called Bright's disease. Nephrotic syndrome is characterized as heavy proteinuria, hypoalbuminemia, hypercholesterolemia (serum cholesterol $>200 \mathrm{mg}$ ), edema and hypertension. Quantitative estimation of 24 hour urinary proteins is usually $>3.5 \mathrm{gms} / 1.73 \mathrm{~m}^{2}$ of body surface area or $>50$ $\mathrm{mg} / \mathrm{kg} /$ day. Proteinuria less than this range, but associated with serum albumin $<3.0 \mathrm{~g} / \mathrm{dl}$ was also classified as nephrotic range. ${ }^{[2]}$

Most common causes and conditions associated with nephrotic syndrome were minimal change disease(MCD), focal segmental glomerulosclerosis (FSGS), membranous glomerulonephritis (MGN), membranoproliferative glomerulonephritis (MPGN), diabetic nephropathy (DN), amyloid nephropathy, Systemic lupus erythematosis(SLE) in advanced stage \& IgA nephritis. MCD, also known as nil disease is more common in children also seen in adult and only $60 \%$ cases respond well to steroids and more likely to relapse. Diabetes is common cause of renal failure and nephrotic syndrome in adults. Clinical features of nephrotic syndrome were periorbital and lower limb edema, ascitis, pleural effusion, hypoalbuminemia, tiredness, breathlessness, fluid overload, acute renal failure, pulmonary thromboembolism \& dyslipidemia. Complications of nephrotic syndrome were hypercoagubility, atherosclerosis, renal vein thrombosis and high susceptibility for infections. Renal biopsy is useful for identifying the specific diagnosis, assessing the level of disease activity, and for allowing specific decisions about treatment to be made. ${ }^{[3]}$ Definitive diagnosis of nephrotic syndrome can be done on histopathological 
examination EM \& IF is essential for correct diagnosis. Glomerular diseases in tropical countries is vastly different in epidemiology, etiology and natural history from those seen in temperate countries; and their prevalence also varies according to socio-economic conditions, race, age and indications for renal biopsy. ${ }^{[4]}$ Over the last few years, studies have shown a changing pattern of these diseases.

The present study was conducted to know the histopathological spectrum of nephrotic syndrome in adults, in relation to the incidence and distribution in various adult age group, gender with clinicopathological, electron microscopy and immunoflurescence correlation at our institute during a 16 years period to ascertain any changes in the spectrum if any of these diseases.

\section{Materials and Methods}

All adults between 15 years and 85 years of age with nephrotic syndrome undergone renal biopsy over the 16 years period from, January 2000 to December 2015 were included in this retrospective study. Blood samples were checked for hemoglobin, platelet count, ESR, serum creatinine, blood urea, lipid profile and 24 hour urine protein for all patients. The percutaneous biopsy was done under continuous monitoring (real time USG procedure). At the time of biopsy whenever possible two cores were obtained for electron microscopic examination and immunofluorescence using antibodies for $\mathrm{IgG}, \mathrm{IgA}$, $\mathrm{IgM}$ and $\mathrm{C} 3$. None of the patients had a previous biopsy and as per the protocol of the treating adult nephrologists none underwent a repeat biopsy. Biopsies were processed and stained with routine hematoxyline and eosin stain, special stains like periodic acid schiff (PAS) and silver impregnation were done whenever required. On light microscopy the lesions were classified as adequate if five complete glomeruli were seen. However the changes, if diagnostic and pathognomic of the lesion were seen even in one glomerulus then, the biopsy was termed adequate in spite of not fulfilling the above criterion. Cases were classified on histomorphology into various groups like MCD, FSGS, MGN, MPGN, diabetic nephropathy, amyloid nephropathy, IgA nephropathy, SLE etc. Electron microscopy (EM) and Immuonofluorescence (IF) findings were correlated with histopathology. All data was entered on Microsoft excel sheet and analyzed by using descriptive statistic.

\section{Result}

Total 634 biopsies were received in our institute over the study period of 16 years from January 2000 to December 2015. Out of which $263(41.48 \%)$ biopsies performed were from more than 15 years adult patients with nephrotic syndrome. On light microscopy, total 235 (89.35\%) renal biopsies were adequate. The ratio of male (148 patients) to female (87 patients) was 1.7:1, highest male predominance was noted in diabetic nephropathy which was $4: 1$. While nephrotic syndrome associated SLE was noted exclusively in female in our study. Clinically, all the patients had edema, $26 \%$ were hypertensive while $36 \%$ had oliguria. Microscopic hematuria was observed in 23 patients $(9.78 \%)$. Average $24 \mathrm{hr}$ urine protein excretion was $5.8 \mathrm{~g}$, serum creatinine was $2.15 \mathrm{mg} / \mathrm{dl}$, while one patient was positive for hepatitis B surface antigen.

\section{Spectrum of Glomerular Lesions}

Primary glomerular diseases accounted for 184(78.3\%) cases, the commonest histomorphological pattern was MCD $62(26.38 \%)$ cases followed by MPGN(38 cases) \& FSGS(37 cases) and secondary glomerular diseases for $51(21.7 \%)$ of cases most common in amyloidosis $17(7.23 \%)$ cases followed by diabetic nephropathy in 15 cases $(6.38 \%$ ). Nine cases of nephrotic syndrome were in end stage renal disease at the time of diagnosis[Table 1]. In age group of 15-25 years minimal change disease followed by focal segmental glomerulosclerosis and membranoproliferative glomerulonephritis were common. Diabetic nephropathy and membranous glomerulonephritis were predominantly seen in late adulthood [Table 1]. Electron microscopy was available in 86 cases (36.6\%) out of 235 cases. Ten ( $9 \%$ ) biopsies were inconclusive and 15 $(13.5 \%)$ biopsies were inadequate. High rate of positive correlation with light microscopic findings was observed with MCD, MPGN, MGN, Amyloidosis, and SLE. In FSGS, diabetic nephropathy, IgA nephropathy correlation was not observed in 33\% cases [Table 2]. Light microscopy findings correlated with electron microscopy findings in 79 cases $(91.86 \%)$ out of 86 cases where electron microscopy was available. However, discrepancy was seen in 11 cases $(12.79 \%)$ out of 86 cases. Final diagnosis was given based on light microscopy, immunofluorescence, electron microscopy and serological findings. Poor outcome of diabetic nephropathy, focal segmental glomerulosclerosis and amyloidosis was noted while outcome of minimal change disease was good in our study.

\section{Discussion}

This work reports on a 16 years of retrospective analysis of 634 cases of adult renal biopsies in a single tertiary care referral institute in Mumbai. Out of which 235 cases $(89.35 \%)$ were adequate biopsies. Age more than 15 years is an indication for biopsy; hence all cases were subjected to biopsy. Of all the renal biopsies done over this period, nephrotic syndrome was the most frequent indication for renal biopsy accounting for 263 cases $(41.48 \%)$ in adult's age group [Table 1]. Sabir $\mathrm{S}$ et al ${ }^{[5]}$ from their study from a 
tertiary care naval hospital in Karachi, Pakistan found that the most common indication of renal biopsy was nephrotic syndrome $(43.3 \%)$ and Primary glomerulonephritides (76.6\%) were predominant overall lesions. N Balkrishnan et al, ${ }^{[6]}$ observed nephrotic syndrome in $65.40 \%$ of cases of various clinical syndromes. This is similar to that reported in various studies around the world, including India and Pakistan. ${ }^{[6,7]}$

Age and gender wise distribution: As age advances from 15 years to 85 years incidence of nephrotic syndrome decreased sequentially in recent study [Table 2]. In our study overall male predominance was seen with male to female ratio of 1.7: 1. Highest male predominance (4:1) was seen in diabetic nephropathy followed by Amyloidosis (2.4:1) \& in membranous glomerulonephritis (2.1:1). While systemic lupus nephritis was seen exclusively in female $(0: 6,100 \%)$ in our study [Table 3].This reflects the increased prevalence of SLE in females. All recently published studies worldwide showed a similar pattern. ${ }^{[6,7]}$ A.R.Reshi et al, ${ }^{[7]}$ also observed male predominance and $\mathrm{N}$ Balkrishnan et al, observed marked female predominance in SLE similar to our study. In our study, In 15-45 years of age group 185 out 235 (78.72\%) cases were seen.MCD was the most common glomerular legion in patients less than 45 years of age while MGN was most common in patients greater than 45 years [Figure 2]. N Balkrishnan et al, observed that majority minimal change disease, membranoproliferative glomerulonephritis in age group 15-34 years similar to our study.

\section{Histopathological distribution of glomerular lesions:} Primary glomerular diseases was the most prominent renal disease in our study accounted for $78.3 \%$ cases of nephrotic syndrome as well as in all other studies, ${ }^{[8,9,10,11]}$ while amyloidosis was the most common secondary cause. The underlying etiology of nephrotic syndrome is variable all over the world. In our study, the most commonest cause was minimal change disease (62 cases, $26.38 \%$ ), followed by membranoproliferative glomerulonephritis (38 cases, $16.17 \%$ ) and focal segmental glomerulonephritis (37 cases, $15.74 \%$ ) were the commonest histological type [ Table 2]. Reshi A.R. et al, Agarwal S.K.et al, Dash S. C. et al, Chang Jae Hyun et al ${ }^{[12]}$ observed that minimal change disease was $33.52 \%, 37 \%$ \& $15.5 \%$ respectively was the most common histological type of nephrotic syndrome in their studies similar to our study.

Histopathology of minimal change disease revealed unremarkable glomeruli on hematoxylin and eosin, PAS and silver staining (Figure 1A). Immunofluorescence was available in 12 cases, out of which 7 cases showed positivity for IgM. Ten cases showed IgG negative, 12 cases were IgA and C3 negative. Electron microscopy was available in 31 cases, which revealed flattening and fusion of the visceral epithelial cells (Figure 1B). In membranoproliferative glomerulonephritis, increase in mesangial cellularity and matrix on hematoxylin and eosin staining (Figure 2A). Silver staining showed splitting of glomerular capillary basement membrane typically described as tram tracking (Figure 2B). Immunofluorescence was available in 15 cases, out of which 10 cases showed linear C3 deposits along capillary wall. Five cases showed IgG deposits in the mesangium, out of which 3 were weakly positive. Eight cases had IgM deposits in mesangium and 3 showed IgA deposits) (Figure 2C). Electron microscopy was available in 11 cases and revealed thickened capillary due to interposed mesangial cells, mesangial matrix and electron dense subendothelial deposits (Figure 2D). Histology of FSGS, revealed 15 cases with peripheral sclerosis (Figure 3B), 7 cases with collapsing glomerulopathy (Figure 3A), 8 cases with perihilar sclerosis (Figure 3C) and 5 cases with tip lesion. Immunofluorescence was available in 13 cases. IgM was positive in mesangium in 8 cases with 5 cases showed C3 positivity, 4 showed IgG positivity. Electron microscopy was available in 10 cases. Positive correlation was seen in 6 cases. Two showed focal areas of sclerosis (Figure 3D). Wrinkling of glomerular basement membrane was seen in 4 cases. One case showed duplication wrinkling and showed focal areas of sclerosis. Membranous glomerulonephritis, histology revealed on $\mathrm{H}$ and $\mathrm{E}$ thickening of basement membrane , confirmed on periodic acid Schiff (PAS) staining (Figure 4A). Silver stain showed spikes along the capillary basement membrane (Figure 4B). Immunofluorescence was available in 12 cases. Seven cases showed granular deposits in IgG and 6 cases showed C3 positivity while 2 cases showed IgM positivity (Figure 4C). Electron microscopy was available in 9 cases. Showed subepithelial deposits in contact with and indenting the visceral epithelial layer (Figure 4D).

Diabetic nephropathy microscopy revealed increase in solid spaces of tuft and Kimmelstiel-wilson nodules (Figure $5 \mathrm{~A}$ ) with few glomerular lobular sclerosis confirmed on periodic acid Schiff (PAS) stain. Immunofluorescence was available in 6 cases. Four cases showed IgG diffusely deposited along the basement membrane, 3 cases showed IgM positivity and 3 cases showed IgA positivity. Deposition of protein seen in linear pattern, narrowing and thickening of renal vasculature. Electron microscopy was available in 5 cases. Four cases showed positive correlation with light microscopy and showed showing increase in mesangial cellularity with thicker capillary basement membrane. One case was diagnosed as membranoproliferative glomerulonephritis on electron 
microscopy. Lupus nephritis (SLE) histology revealed showed diffuse lobular accentuation. WHO class IV showing glomerular capillary wall thickened (wire loop) (Figure 5B) and increase in mesangial matrix. PAS stain showed splitting of capillary wall and silver stain showed double countered glomerular basement membrane. Immunofluorescence was available 3 cases. IgG positivity in 3 cases, 2 cases $\mathrm{C} 1 \mathrm{Q}$ positive, 2 case show IgA positivity and $\mathrm{C} 3$ positive in 1 case. Electron microscopy was available in 6 cases with subepithelial deposits. Amyloidosis histology revealed glomerular capillary wall show irregular thickening with expansion of mesangium confirmed on PAS stain (Figure 5C). Silver stain showed irregular spikes. Congo red stain showed positivity which is apple green birefringence under polarized light in 8 cases (Figure 5D). Immunofluorescence was available in 5 cases and negative. Electron microscopy was available in 7 cases showing linear, non branching fibrils.

A summary of other studies from India is presented in [Table 3], found MCD to be the most common cause of nephrotic syndrome. The study done from Vellore in 1970's by Date et al noted that MCD accounted for about $35 \%$ of all cases of nephrotic syndrome. Similarly, studies from Delhi by Agarwal S.K. et al found (37\%) and Aggrawal et al from Rohtak found (33.3\%), MCD cases responsible for more than one-third of nephrotic syndrome. The Das et al from Hyderabad also found similar observation with MCD in $21.8 \%$ cases of nephrotic syndrome for a study period of 1990 to 2008. Rathi et al from Chandigarh showed increasing trend of FSGS, this trend has not been observed in our study. In a year 2010-12 study published from Kolkata, Golay et al ${ }^{[1]}$ found that FSGS was underlying disease in $27.4 \%$ of their patients making it the most common one However, they found MCD in $27.1 \%$ of cases, making it the second most common cause of nephrotic syndrome. This figure is very similar to our present data, where MCD were responsible for $26.38 \%$ of cases.

A comparative studies with Asian region is summarized in [Table 4 ], shows certain interesting and conflicting data. Study by Chang et al, ${ }^{[12]}$ from Korea MCD as a most common in nephrotic syndrome similar to our present findings. However Zhou et al ${ }^{[13]}$ from China observed $25.3 \%$ cases of MCD which is similar $26.38 \%$ cases of MCD of our present study. Studies from Nepal done by Zhou et al ${ }^{[13]}$, Garyal et al ${ }^{[14]}$, from China and I. M. Onwubuya et al ${ }^{[15]}$ from Nigeria shown that most common cause is MGN responsible for $29.5 \%, 42.3 \%$ and $30.6 \%$ cases of nephrotic syndrome respectively. Sabir S et al and Kazi et al ${ }^{[16]}$ from Pakistan found FSGS to be the most common lesion among Primary glomerulonephritides .This may be due to demographical, geographical and racial characteristics, differences in indication of renal biopsy, analyzed clinical syndromes and variation in pathological classification. Therefore for drawing accurate conclusions were difficult by comparison with different data of Asian studies.

Table 1: Age and sex wise distribution of various histomorphological patterns of adults nephrotic syndrome.

\begin{tabular}{|c|c|c|c|c|c|c|c|c|c|c|c|c|c|c|c|}
\hline \multirow{2}{*}{$\begin{array}{l}\text { Histomorpho logical } \\
\text { pattern }\end{array}$} & \multicolumn{2}{|c|}{$15-25$ yrs } & \multicolumn{2}{|c|}{$26-35$ yrs } & \multicolumn{2}{|c|}{$36-45 \mathrm{yr}$} & \multicolumn{2}{|c|}{$46-55 \mathrm{yr}$} & \multicolumn{2}{|c|}{$56-65$ yrs } & \multicolumn{2}{|c|}{$66-75$ yrs } & \multicolumn{2}{|c|}{$76-85$ yrs } & \multirow{2}{*}{ Total } \\
\hline & M & $F$ & M & $F$ & M & $F$ & M & $\mathrm{F}$ & M & $\mathrm{F}$ & M & $\mathrm{F}$ & M & $\mathbf{F}$ & \\
\hline MCD & 22 & 9 & 9 & 8 & 6 & 5 & 1 & 0 & 1 & 1 & 0 & 0 & 0 & 0 & $62(26.38 \%)$ \\
\hline MPGN & 10 & 8 & 2 & 5 & 5 & 1 & 2 & 1 & 4 & 0 & 0 & 0 & 0 & 0 & 38 (16.17\%) \\
\hline FSGS & 13 & 5 & 4 & 3 & 5 & 2 & 0 & 2 & 2 & 0 & 0 & 1 & 0 & 0 & 37 (15.74\%) \\
\hline MGN & 2 & 1 & 8 & 3 & 3 & 2 & 7 & 2 & 1 & 2 & 0 & 0 & 0 & 0 & 31 (13.19\%) \\
\hline $\mathrm{DN}$ & 0 & 0 & 3 & 1 & 1 & 0 & 4 & 1 & 2 & 1 & 1 & 0 & 1 & 0 & $15(6.38 \%)$ \\
\hline AMYLOID & 1 & 0 & 5 & 2 & 2 & 0 & 1 & 2 & 2 & 1 & 1 & 0 & 0 & 0 & $17(7.23 \%)$ \\
\hline SLE & 0 & 3 & 0 & 2 & 0 & 1 & 0 & 0 & 0 & 0 & 0 & 0 & 0 & 0 & $6(2.55 \%)$ \\
\hline $\lg \mathrm{A}$ & 2 & 0 & 0 & 0 & 0 & 1 & 0 & 0 & 0 & 0 & 0 & 0 & 0 & 0 & $3(1.27 \%)$ \\
\hline ESRD & 4 & 2 & 1 & 0 & 0 & 0 & 0 & 2 & 0 & 0 & 0 & 0 & 0 & 0 & $9(3.8 \%)$ \\
\hline DPGN & 2 & 0 & 2 & 0 & 0 & 2 & 1 & 0 & 0 & 1 & 0 & 0 & 0 & 0 & $8(3.4 \%)$ \\
\hline RPGN & 1 & 0 & 1 & 0 & 0 & 0 & 0 & 0 & 0 & 1 & 0 & 0 & 0 & 0 & $3(1.27 \%)$ \\
\hline APSGN & 1 & 0 & 0 & 1 & 0 & 1 & 0 & 0 & 1 & 0 & 0 & 0 & 0 & 0 & $4(1.7 \%)$ \\
\hline TIN & 0 & 1 & 0 & 0 & 0 & 1 & 0 & 0 & 0 & 0 & 0 & 0 & 0 & 0 & $2(0.85 \%)$ \\
\hline TOTAL & 58 & 29 & 35 & 25 & 22 & 16 & 16 & 10 & 13 & 7 & 2 & 1 & 1 & 0 & \multirow{2}{*}{235} \\
\hline Total of $\mathrm{M}$ and $\mathrm{F}$ & \multicolumn{2}{|c|}{87} & \multicolumn{2}{|c|}{60} & \multicolumn{2}{|c|}{38} & \multicolumn{2}{|c|}{26} & \multicolumn{2}{|c|}{20} & & & & \\
\hline
\end{tabular}

MCD: minimal change disease, MPGN: membranoproliferative glomerulonephritis, FSGS: focal segmental glomerulosclerosis, MGN: membranous glomerulonephritis, DN: diabetic nephropathy, SLE: Systemic lupus erythematosis, IgA: IgA nephritis, ESRD: end stage renal disease, DPGN: Diffuse proliferative glomerulonephritis, RPGN: Rapidly progressive glomerulonephritis, APSGN: Acute post streptococcal glomerulonephritis, TIN: tubulointersitial nephritis, $M$ : male, F: female. 
Table 2: Histopathology and electron microscopy correlation.

\begin{tabular}{|l|c|c|c|c|c|}
\hline $\begin{array}{l}\text { Histomorpho logical pattern } \\
\text { (light microscopy) }\end{array}$ & No. of cases & $\begin{array}{c}\text { Positive } \\
\text { correlation }\end{array}$ & $\begin{array}{c}\% \text { of Positive } \\
\text { correlation }\end{array}$ & $\begin{array}{c}\text { Negative } \\
\text { correlation }\end{array}$ & $\begin{array}{c}\% \text { of Negative } \\
\text { correlation }\end{array}$ \\
\hline MCD & 31 & 31 & 100 & 0 & 0 \\
\hline MPGN & 11 & 11 & 100 & 0 & 0 \\
\hline FSGS & 10 & 6 & 66 & 4 & 33.33 \\
\hline MGN & 9 & 9 & 100 & 0 & 0 \\
\hline DN & 5 & 4 & 80 & 1 & 20 \\
\hline AMYLOID & 7 & 7 & 100 & 0 & 0 \\
\hline SLE & 6 & 6 & 100 & 0 & 0 \\
\hline IgA & 3 & 2 & 66.67 & 1 & 33.33 \\
\hline ESRD & 1 & 0 & 0 & 1 & 100 \\
\hline APSGN & 3 & 3 & 100 & 0 & 0 \\
\hline TOTAL & $\mathbf{8 6}$ & $\mathbf{7 9}$ & $\mathbf{9 1 . 8 6}$ & $\mathbf{0 7}$ & $\mathbf{8 . 1 4}$ \\
\hline
\end{tabular}

Table 3: Comparison of glomerular lesions among nephrotic syndrome in adults in different Indian studies.

\begin{tabular}{|c|c|c|c|c|c|c|c|}
\hline Reference & $\begin{array}{l}\text { Date } \\
\text { et al. }{ }^{[8]}\end{array}$ & $\begin{array}{l}\text { Agarwal } \\
\text { et al. }{ }^{[9]}\end{array}$ & $\begin{array}{l}\text { Aggrawal } \\
\text { et al. }{ }^{[10]}\end{array}$ & $\begin{array}{l}\text { Das } \\
\text { et al. }{ }^{[3]}\end{array}$ & $\begin{array}{l}\text { Rathi } \\
\text { et } \text { al }^{[2]}\end{array}$ & $\begin{array}{l}\text { Goyal } \\
\text { et al. } .^{[11]}\end{array}$ & $\begin{array}{l}\text { Present } \\
\text { study }\end{array}$ \\
\hline Year & $1971-85$ & $1987-98$ & 2000 & $1990-2008$ & 2002-07 & 2010-12 & $2000-2015$ \\
\hline Place & Vellore & Delhi & Rohtak & Hyderabad & Chandigarh & Kolkata & Mumbai \\
\hline $\mathbf{N}$ & 1532 & 2250 & 404 & 1615 & 364 & 410 & 235 \\
\hline $\begin{array}{l}\text { Primary glomerular } \\
\text { diseases }\end{array}$ & $\begin{array}{c}1276 \\
(83.3 \%)\end{array}$ & $\begin{array}{c}1316 \\
(58.5 \%)\end{array}$ & $\begin{array}{c}318 \\
(78.7 \%)\end{array}$ & $\begin{array}{c}1278 \\
(79.1 \%)\end{array}$ & $\begin{array}{c}324 \\
(89 \%)\end{array}$ & $\begin{array}{c}361 \\
(88.1 \%)\end{array}$ & $\begin{array}{c}184 \\
(78.3 \%)\end{array}$ \\
\hline MCD & $\begin{array}{c}457 \\
(35.8 \%)\end{array}$ & $\begin{array}{c}487 \\
(37 \%)\end{array}$ & $\begin{array}{c}106 \\
(33.3 \%)\end{array}$ & $\begin{array}{c}279 \\
(21.8 \%)\end{array}$ & $\begin{array}{c}48 \\
(14.8 \%)\end{array}$ & $\begin{array}{c}98 \\
(27.1 \%)\end{array}$ & $\begin{array}{c}62 \\
(26.38 \%)\end{array}$ \\
\hline MPGN & $\begin{array}{c}177 \\
(13.9 \%)\end{array}$ & $\begin{array}{c}153 \\
(11.6 \%)\end{array}$ & $\begin{array}{c}58 \\
(18.2 \%) \\
\end{array}$ & $\begin{array}{c}73 \\
(5.7 \%) \\
\end{array}$ & $\begin{array}{c}58 \\
(17.9 \%) \\
\end{array}$ & $\begin{array}{c}24 \\
(6.6 \%) \\
\end{array}$ & $\begin{array}{c}38 \\
(16.17 \%)\end{array}$ \\
\hline FSGS & $\begin{array}{c}238 \\
(18.6 \%)\end{array}$ & $\begin{array}{c}263 \\
(20 \%)\end{array}$ & $\begin{array}{c}56 \\
(17.6 \%)\end{array}$ & $\begin{array}{c}195 \\
(15.2 \%)\end{array}$ & $\begin{array}{c}99 \\
(30.6 \%)\end{array}$ & $\begin{array}{c}99 \\
(27.4 \%)\end{array}$ & $\begin{array}{c}37 \\
(15.74 \%)\end{array}$ \\
\hline MGN & $\begin{array}{c}174 \\
(13.6 \%)\end{array}$ & $\begin{array}{c}263 \\
(20 \%)\end{array}$ & $\begin{array}{c}54 \\
(16.9 \%)\end{array}$ & $\begin{array}{c}129 \\
(10.1 \%)\end{array}$ & $\begin{array}{c}79 \\
(24.4 \%)\end{array}$ & $\begin{array}{c}89 \\
(24.6 \%)\end{array}$ & $\begin{array}{c}31 \\
(13.19 \%)\end{array}$ \\
\hline DPGN/ PSGN & $\begin{array}{c}32 \\
(2.5 \%)\end{array}$ & - & - & $\begin{array}{c}190 \\
(14.9 \%)\end{array}$ & $\begin{array}{c}9 \\
(2.8 \%)\end{array}$ & $\begin{array}{c}6 \\
(1.6 \%)\end{array}$ & $\begin{array}{c}12 \\
(5.1 \%)\end{array}$ \\
\hline $\begin{array}{l}\text { Secondary } \\
\text { glomerular } \\
\text { diseases }\end{array}$ & $\begin{array}{c}256 \\
(16.7 \%)\end{array}$ & $\begin{array}{c}934 \\
(41.5 \%)\end{array}$ & $\begin{array}{c}86 \\
(21.3 \%)\end{array}$ & $\begin{array}{c}337 \\
(20.9 \%)\end{array}$ & $\begin{array}{c}40 \\
(11 \%)\end{array}$ & $\begin{array}{c}49 \\
(11.9 \%)\end{array}$ & $\begin{array}{c}51 \\
(21.7 \%)\end{array}$ \\
\hline
\end{tabular}

Table 4: Comparison of glomerular lesions among nephrotic syndrome in adults in different Asian studies.

\begin{tabular}{|c|c|c|c|c|c|c|}
\hline Reference & Chang et al.[12] & Zhou et al. ${ }^{[13]}$ & Garyal et al. ${ }^{[14]}$ & I.M.Onwubuya et al. ${ }^{[15]}$ & Kazi et al. ${ }^{[16]}$ & Present study \\
\hline Country & Korea & China & Nepal & Nigeria & Pakistan & India \\
\hline $\mathbf{N}$ & 1818 & 1374 & 137 & 165 & 316 & 235 \\
\hline MCD (\%) & 15.5 & 25.3 & 10.2 & 19.7 & 14.8 & 26.38 \\
\hline MPGN(\%) & 4.0 & 1.5 & 21.9 & 19.7 & 4.3 & 16.17 \\
\hline FSGS(\%) & 5.6 & 6.0 & 8.0 & 15.9 & 39.9 & 15.74 \\
\hline MGN(\%) & 12.3 & 29.5 & 42.3 & 15.9 & 26.6 & 13.19 \\
\hline $\begin{array}{l}\text { DPGN/ } \\
\text { PSGN(\%) }\end{array}$ & - & 0.7 & 2.9 & 12.9 & 2.8 & 5.10 \\
\hline
\end{tabular}




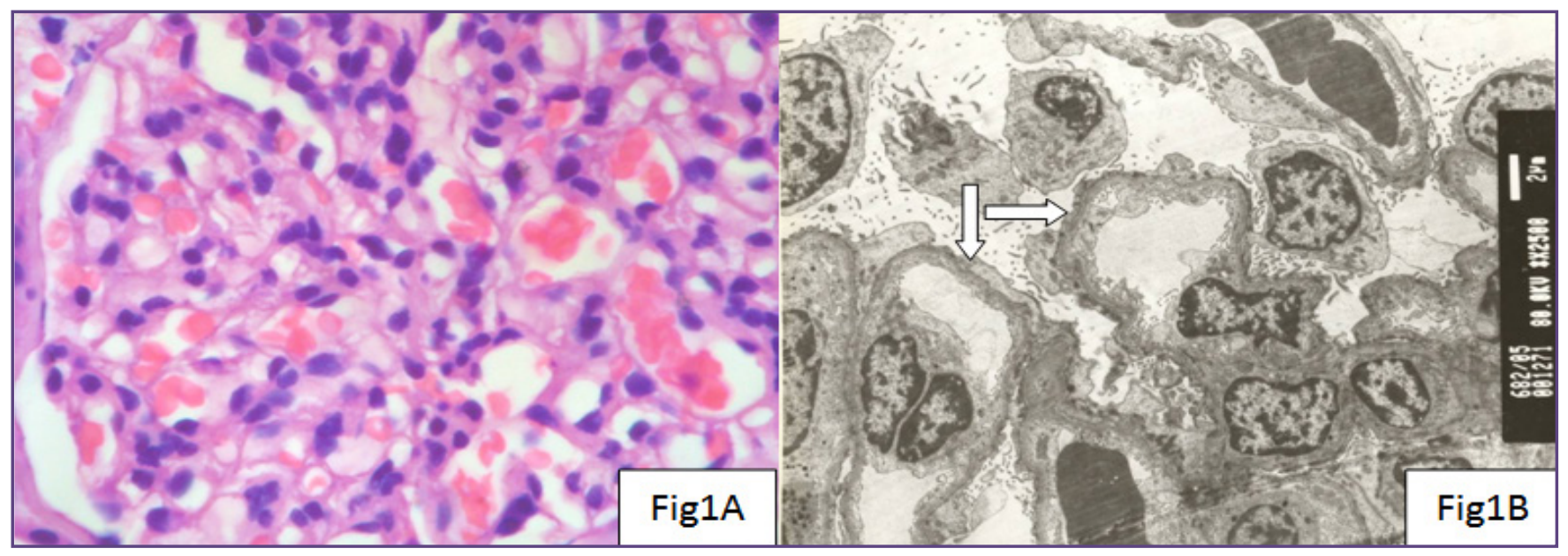

Fig. 1: (1A), Minimal change disease, showing unremarkable glomerulus with patent capillary lumina $\&$ normal mesangial cellularity (H \& E ,100X). Fig (1B), Electron microscopy: Flattening \& fusion of the foot processes (arrows) of the visceral epithelial cells. (uranyl acetate lead citrate, 2500X).

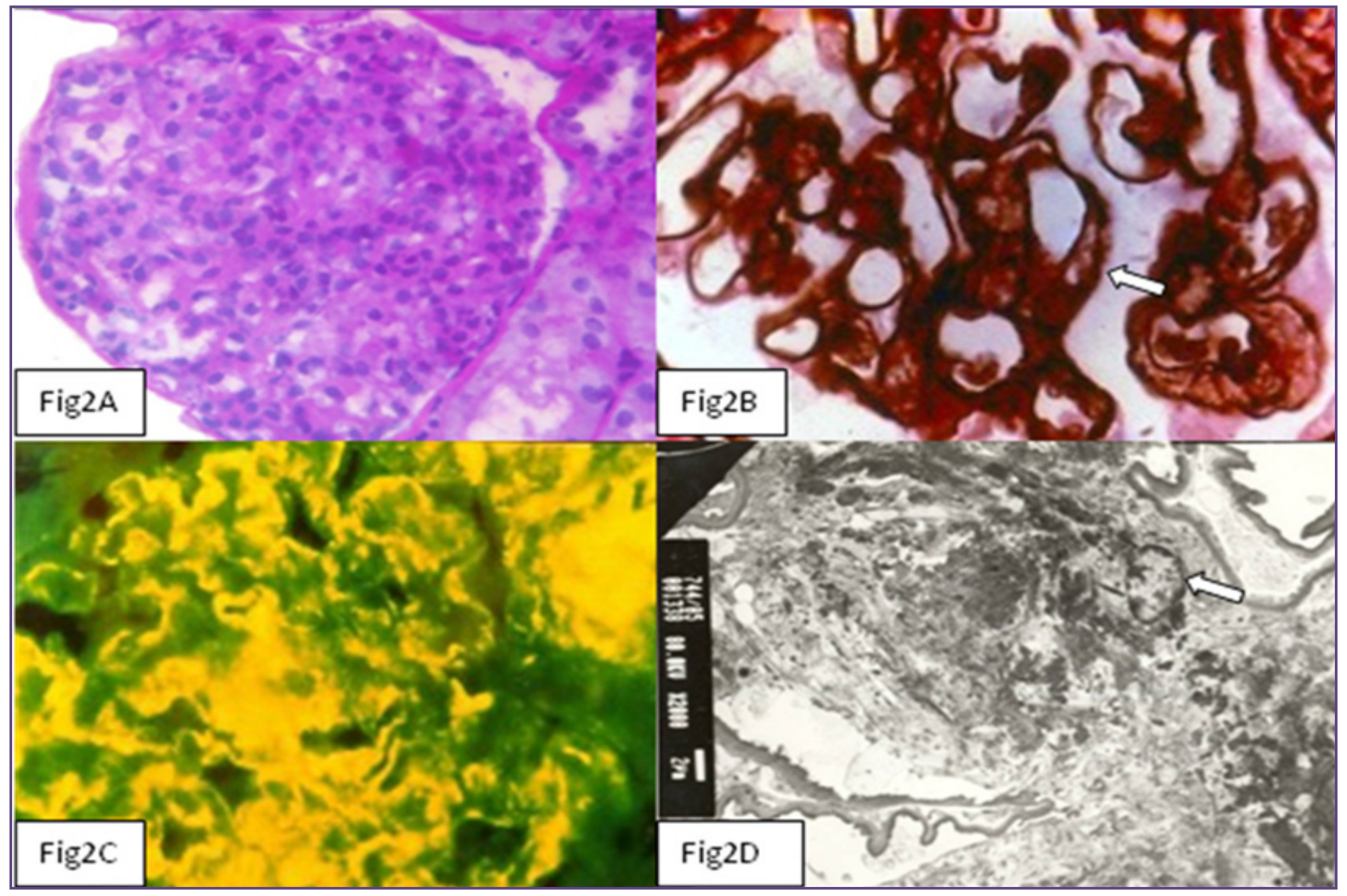

Fig. 2 :(2A),Membranoproliferative glomerulonephritis, Showing mesangial cell proliferation. Lobular accentuation. Increase in mesangial matrix and capillary wall thickening, (PAS, 100X). Fig (2B),Showing splitting (arrow)\{tram tracking\} of the capillary basement membrane, (Silver, 100X). Fig (2C),Immunofluorescence, Note the diffuse, broad capillary loop \& mesangial deposits, (Anti-C3, 100X). Fig(2D), Electron microscopy: Shows widening of the glomerular capillary wall due to mesangial cell interposition (arrow). Note the increase in mesangial matrix \& the electron dense deposits. (uranyl acetate, lead citrate, 2000X). 


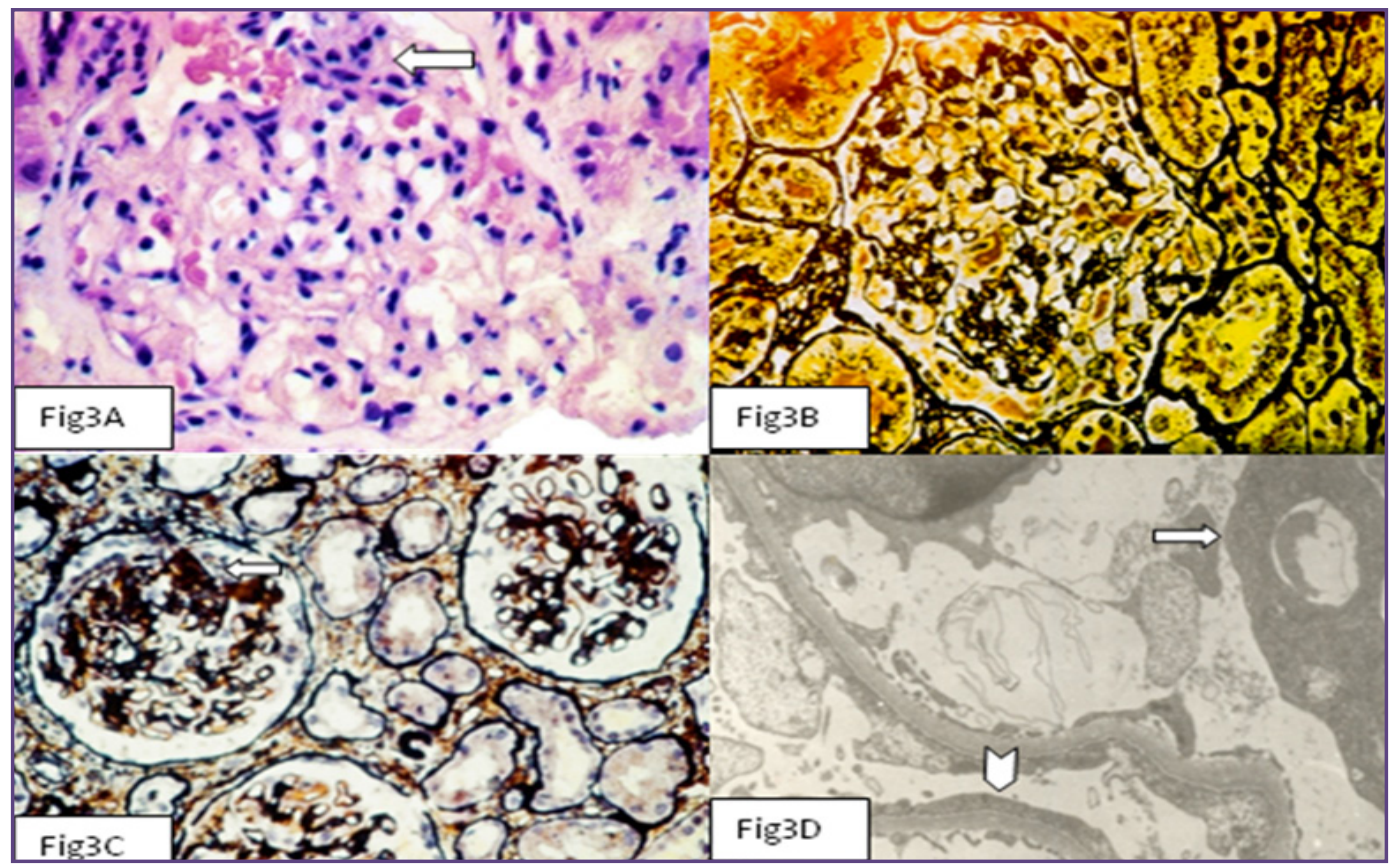

Fig 3: (3A), Focal segmental glomerulosclerosis. Showing focal sclerosis of the glomerulus with collapse of the capillary tuft (top centre) while rest of the glomerulus is unremarkable, (H\&E, 100X). Fig(3B) ,Sclerosed area in the glomerulus (peripheral sclerosis), (Silver stain, 1000X), Fig(3C), Sclerosis in the perihilar region (arrow) of the glomerulus on the left, (Silver stain, 450X). Fig(3D), Electron microscopy: Note the focal area of sclerosis (arrow) and the flattening of the foot processes (arrow head), (uranyl lead citrate, 8000X).

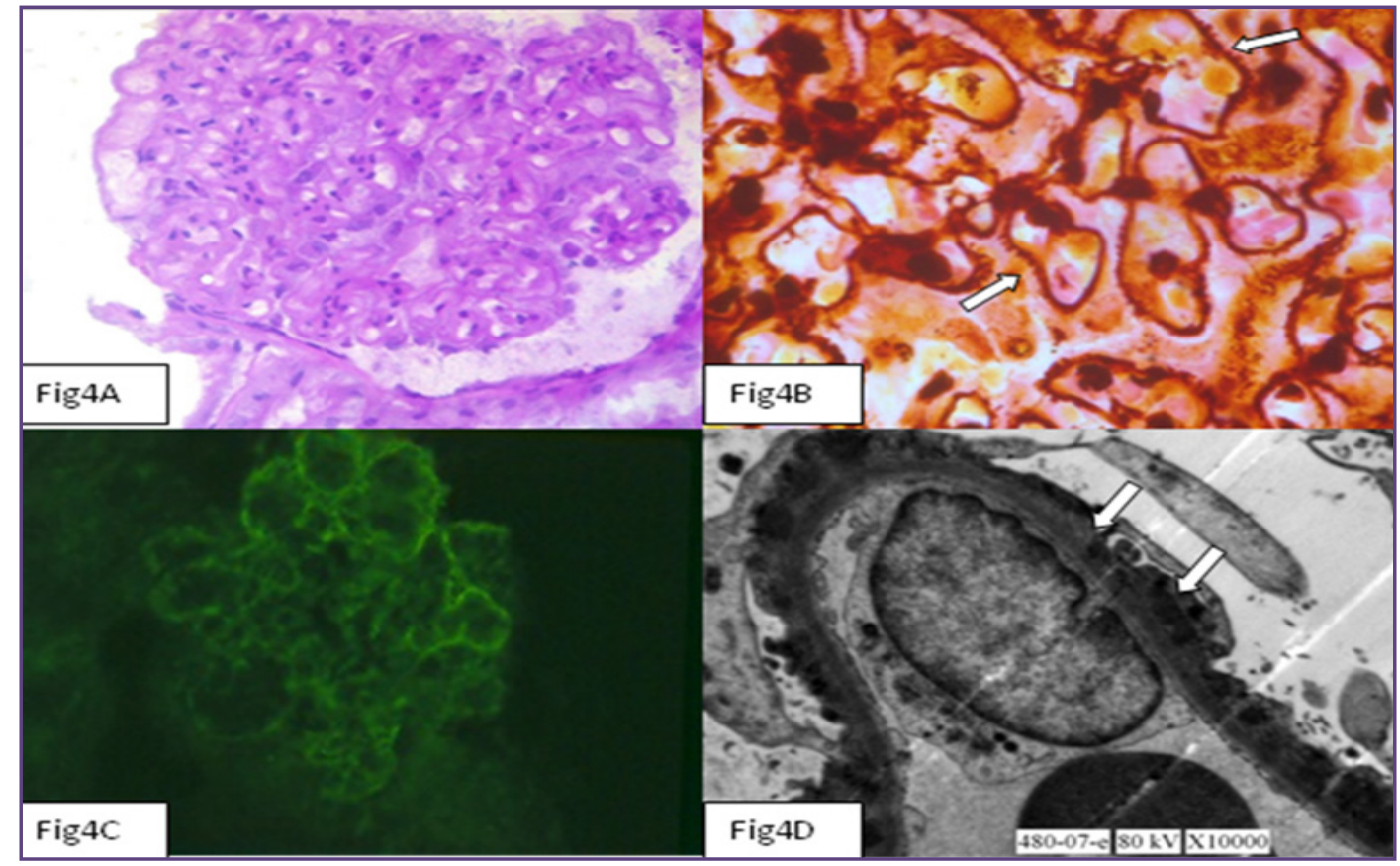

Fig. 4: (4A), Membranous glomerulonephritis. Showing the thickening of the glomerular capillary walls without increase in the cellularity (PAS, 100X). Fig (4B), Spikes (arrows) on the sub epithelial surface of glomerular basement membrane (Methanamine silver stain ,200X). Fig (4C), Immunofluorescence: showing diffuse, finely granular deposits outlining the glomerular capillary walls (Anti-IgG, 100X). Fig (4D), Electron microscopy : Showing sub epithelial deposits (arrows) in contact with \& indenting the visceral epithelial cells (10000X). 


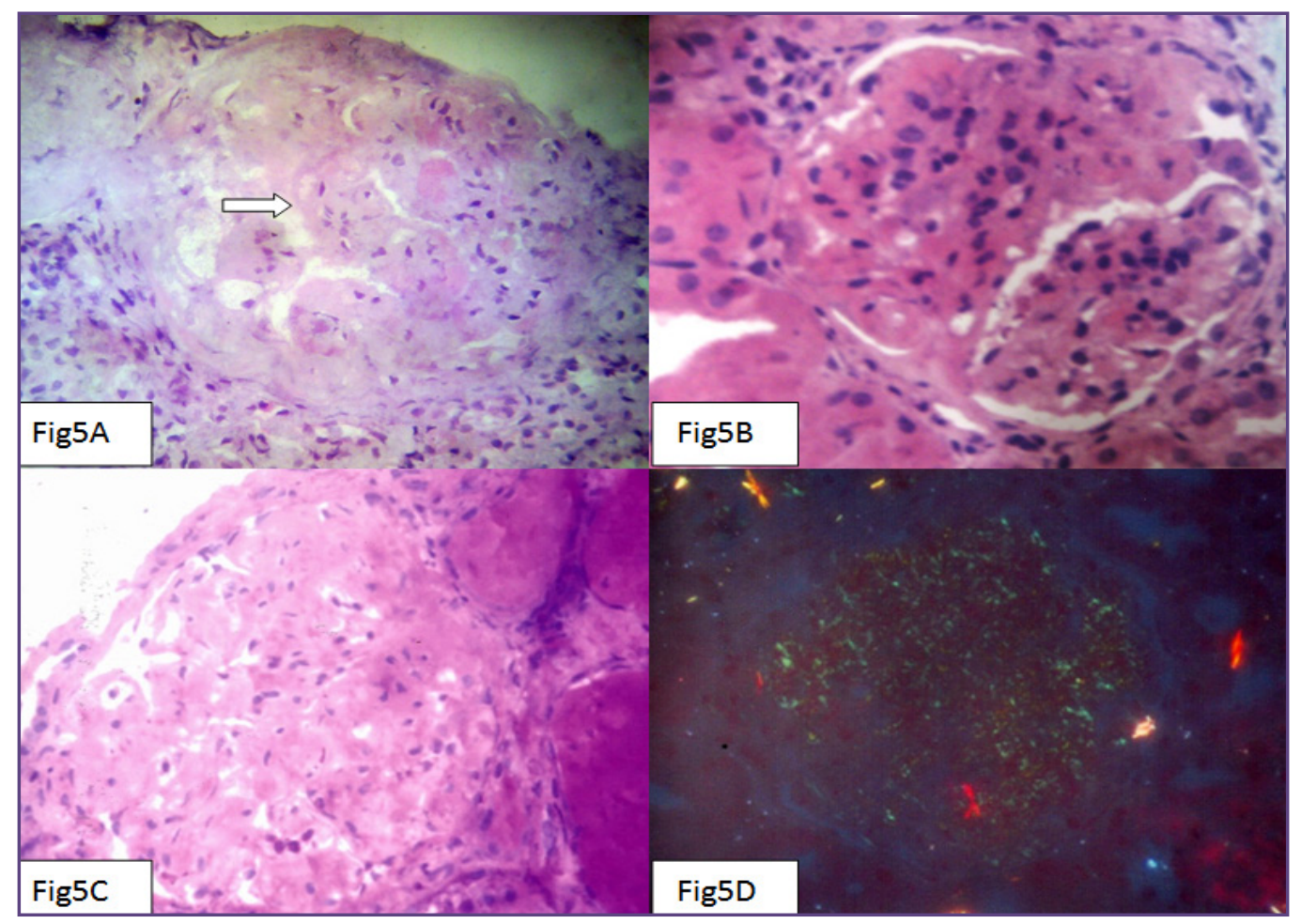

Fig. 5: (5A), Diabetic nephropathy. Showing kimmelstiel - wilson nodules (arrows) (H\&E, 40X). Fig(5B), Lupus nephritis, WHO Class IV lesion. Glomerular capillary walls are segmentally thickened by wire loop deposits (H \& E, 400X). Fig (5C), Diffuse mesangial pattern of glomerular amyloidosis indicated by a cellular weakly PAS positive mesangial expansion (PAS, 400X).Fig(5D), Amyloidosis. Deposits of amyloid exhibiting - apple green birefringence under polarized light ( Congo red stain, 100X).

\section{Conclusion}

This study highlights that Minimal Change Disease is the most common cause of nephrotic syndrome in adult male patients while Membranous glomerulonephritis and Diabetic nephropathy are the most common lesions in more than 45 years of age. Electron microscopy was available in only 86 cases (36.6\%) out of 235 cases and Immunoflurescence was performed in $31.5 \%$ of cases. Light microscopy findings are well correlated with electron microscopy findings in $91.86 \%$ of cases .Hence greater use of these advance dignostic methods can further change the adult nephrotic syndrome spectrum. Even though in past studies, the histological spectrum of nephrotic syndrome was similar in different parts of India except for the study carried out in Chandigarh showing increasing trend towards FSGS But, there has been considerable heterogeneity in histological spectrum of nephrotic syndrome in adjacent Asian countries. It is essential as well as necessary to maintain a central renal biopsy registry with increase participation of more nephrology centers of India for obtaining the accurate incidence, spectrum and distribution of adults nephrotic syndrome.

\section{Acknowledgements}

Department of Pathology, Jaslok Hospital and Research Centre, Mumbai.

\section{Reference}

1. Berry D, Mackenzie C, Richard Bright. Physician in an Age of Revolution and Reform, London.1992; 1789-1858.

2. Rathi M, Bhagat R. L, Mukhopadhyay P, et al.Changing histologic spectrum of adult nephrotic syndrome over five decades in north India: A single center experience. Indian J Nephrol. Mar-Apr 2014; 24(2): 86-91.

3. Das U, Dakshinamurty K V, Prayaga A. Pattern of biopsyproven renal disease in a single center of south India: 19 years experience. Indian J Nephrol. 2011;21:250-7.

4. Sakhuja V, Jha V, Ghosh A K, Ahmed S, Saha T K. Chronic renal failure in India. Nephrol Dial Transplant. 1994; 9:871-2.

5. Sabir S, Mubarak M, Ul-Haq, Bibi A. Pattern of biopsy proven renal diseases at PNS SHIFA, Karachi:A cross sectional survey. J Renal Inj Prev.2013 Oct 10;2(4):133-7.

6. Balakrishnan N, John G T, Korula A, et al. Spectrum of biopsy proven renal disease and changing trends at a tropical tertiary care centre 1990-2001. Indian J Nephrol. 2003; $13: 29-35$. 
7. Reshi AR, Bhat MA, Najar MS, et al. Etiological profile of nephrotic syndrome in Kashmir. Indian Journal of Nephrol 2008; 18(1): 9-12.

8. Date A, Raghavan R, John T J, Richard J, Kirubakaran M G, Shastry J C. Renal disease in adult Indians: A clinicopathological study of 2,827 patients. Q J Med. 1987;64:729-37.

9. Agarwal S K, Dash S C, et al. Spectrum of renal diseases in Indian adults. J Assoc Physicians India. 2000;48:594-600.

10. Aggarwal H K, Yashodara B M, Nand N, Sonia, Chakrabarti D, Bharti K. Spectrum of renal disorders in a tertiary care hospital in Haryana. J Assoc Physicians India. 2007;55:198-202.

11. Golay V, Trivedi M, Kurien A A, Sarkar D, Roychowdhary A, Pandey R. Spectrum of nephrotic syndrome in adults: Clinicopathological study from a single center in India. Ren Fail. 2013;35:487-91.
12. Chang J H, Kim D K, Kim H W, et al. Changing prevalence of glomerular diseases in Korean adults: A review of 20 years of experience. Nephrol Dial Transplant. 2009;24:2406-10.

13. ZhouFD, Shen HY, Chen M, etal. The renal histopathological spectrum of patients with nephrotic syndrome: An analysis of 1523 patients in a single Chinese centre. Nephrol Dial Transplant. 2011;26:3993-7.

14. Garyal, Kafle R K et al. Hisopathological spectrum of glomerular disease in Nepal: A seven-year retrospective study. Nepal Med Coll J. 2008;10:126-8.

15. Onwubuya IM , Adelusola KA, Sabageh D, Ezike K. N, Olaofe OO. Biopsy proven renal disease in Ile-Ife, Nigeria: A histopathologic review.Indian J Nephrol. 2016 Jan-Feb; 26(1): 16-22.

16. Kazi J I, Mubarak M, Ahmed E, Akhter F, Naqvi S A, Rizvi S A. Spectrum of glomerulonephritides in adults with nephrotic syndrome in Pakistan.Clin Exp Nephrol. 2009; 13:38-43.

*Corresponding author:

Dr. Ganesh Ramdas Kshirsagar; 96/3403,C-wing,The Neharu Nagar Suryadarshan CHS Ltd, Neharu Nagar Kurla-East, Mumbai (India), 200024

Phone: +91 9821505456

Email: gkshirsagar31@yahoo.in

Date of Submission : 09.02.2017

Date of Acceptance : 09.06.2017

Financial or other Competing Interests: None.

Date of Publication : 19.12.2017 